\title{
PODIPLOMSKI ŠTUDIJ NA ODDELKU ZA GEOGRAFIJO FILOZOFSKE FAKULTETE UNIVERZE V LJUBLJANI
}

\section{SPLOŠNO}

I. SMERI (z usmeritvami):

- Didaktika geografije

- Ekološka geografija

- Fizična geografija

- Geografija krasa

- Geografske osnove regionalnega planiranja

- Geografija turizma

- Regionalna geografija

- Socialna in politična geografija

\section{TEMELJNI CILJI PROGRAMA}

Podiplomski študij geografije izobražuje strokovnjake, ki so usposobljeni za samostojno znanstveno-raziskovalno in pedagoško delo na raziskovalnih inštitutih, visokošolskih ustanovah in drugih ustanovah, kjer so potrebni podiplomsko izobraženi kadri s področja geografije. Pri podiplomskem študiju kandidati poglobijo in razširijo metodološko znanje in se poglobljeno seznanijo $\mathrm{s}$ teorijo in metodologijo raziskovalnega dela $\mathrm{v}$ geografiji. Usposobijo se za reševanje konkretnih znanstvenih problemov.

\section{TRAJANJE ŠTUDIJA}

Podiplomski magistrski študij geografije traja 2 leti (plus čas za izdelavo naloge) in vsebuje največ 450 ur predavanj, seminarjev in vaj, kar ustreza 120 kreditnim točkam. Študent ima možnost najmanj $10 \%$ predavanj, seminarjev in vaj opraviti v drugih študijskih programih na istem oziroma drugih visokošolskih zavodih doma in v tujini. Študent ima možnost najmanj $25 \%$ študijskih obveznosti, izraženih v kreditnih točkah, opraviti z individualnim raziskovalnim delom.

Doktorski študij traja 4 leta od dneva, ko je bila sprejeta tema disertacije na Univerzi v Ljubljani. Doktorski študij z neposrednim prehodom traja 4 leta. Prvi dve leti se izvajata po pravilih za magistrski študij, drugi dve pa kot individualno raziskovalno delo.

\section{POVEZANOST Z DRUGIMI PROGRAMI}

Program je nadgradnja dodiplomskega študija geografije. $Z$ dodatnimi diferencialnimi izpiti iz uvoda $v$ geografijo, fizične geografije, družbene geografije in regionalne geografije se lahko vanj vključijo tudi diplomanti drugih sorodnih humanističnih, družboslovnih in naravoslovnih strok. 
Program podiplomskega študija geografije je vsebinsko in organizacijsko primerljiv s programi podiplomskega študija geografije na ostalih srednjeevropskih univerzah in se nanje tudi navezuje.

\section{VKLJUČEVANJE V KREDITNI(E) SISTEM(E) ŠTUDIJA}

Magistrski študij geografije je ovrednoten s 120 kreditnimi točkami, doktorski študij pa z 240 kreditnimi točkami (60 točk za vsako leto). Pri magistrskem študiju odpade 30 kreditnih točk na magistrsko delo in individualno raziskovalno delo, 90 kreditnih točk pa na največ 6 predmetov, ki so lahko različno ovrednoteni glede na njihov obseg. Razen predmetov, ki so v predmetniku tega programa, veljajo kot enakovredni v tem kreditnem sistemu tudi drugi predmeti iz podiplomskih programov naravoslovnih, družboslovnih in humanističnih ved, ki so po dogovoru z mentorjem in kandidatom ter ustreznim oddelkom Filozofske fakultete ali druge visokošolske ustanove vključeni v individualne programe.

Študent doseže predpisano število kreditov z izborom (po dogovoru z mentorjem), ki vsebuje: 2 skupna predmeta za vse kandidate podiplomskega študija geografije (skupina A), 2 predmeta za izbrano smer (skupina B) in dva specialistična predmeta (skupina C), ki sta vezana na magistrsko delo ali raziskovanje kandidata. Vsaj en predmet iz skupin B ali C študent izbira izven matičnega oddelka, bodisi v okviru Filozofske fakultete, ostalih fakultet Univerze v Ljubljani ali $v$ tujini.

Kreditne točke za uspešno opravljeno delo kandidat pridobi na osnovi različnih oblik preverjanja znanja (pisni, ustni izpit, seminarska naloga). Izpit iz posameznega predmeta se opravlja po končanem predavanju oz. seminarju. Če je predmet predviden v obeh letnikih, pa po zaključku 3. semestra.

Pri interdisciplinarno zastavljenem programu se lahko do ene polovice programa nadomesti s predmeti, ki jih kandidat posluša zunaj oddelka. Merila za vrednotenje njegovega dela se dogovorijo s sodelujočim oddelkom ali ustanovo ob pripravi individualnega študijskega programa.

Študentom se priznajo tudi rezultati, ki jih doseže v okviru podiplomskega študija na tujih univerzah. Osnova za upoštevanje študija, opravljenega v tujini, je primerjava študijskega programa z zahtevami tega programa.

\section{VKLJUČEVANJE PROGRAMA V MEDNARODNO SODELOVANJE}

Študijski program Geografija - podiplomski študij predvideva več oblik mednarodnega sodelovanja:

- izbor posameznih specialističnih predmetov na tujih visokošolskih ustanovah,

- sodelovanje tujih strokovnjakov kot mentorjev in somentorjev pri izdelavi magistrskega dela in doktorske disertacije, vabljena predavanja tujih strokovnjakov v okviru rednega programa podiplomskega študija,

- opravljanje laboratorijskih in drugih analiz, za katere pri nas ni ustrezne opreme, v tujini,

- sodelovanje tujih strokovnjakov pri naših podiplomskih ekskurzijah in terenskem delu $\mathrm{v}$ tujini in sodelovanje naših podiplomskih učiteljev in študentov pri mednarodnih obiskih pri nas. 


\section{RAZISKOVALNE OZ. STROKOVNE PODLAGE ZA IZVEDBO PROGRAMA (reference zavoda in nosilcev programa)}

Oddelek za geografijo razvija podiplomski študij na področjih, na katerih ima za razvoj in izvajanje raziskovalnega dela zagotovljeno kadrovsko in materialno infrastrukturo. Visokošolski učitelji se usmerjajo v številne strokovne specializacije, so metodološko dovolj razgledani in strokovno usposobljeni. Kandidati za magistrski študij se zato lahko odločajo za smer študija, ki je njihovemu interesu in sposobnostim najbližja.

Oddelek razpolaga z bogato knjižnico, ki pokriva vsa področja geografije. Ima tudi bogato kartografsko zbirko in solidno opremljen fizičnogeografski laboratorij. Na razpolago je računalniška in programska oprema. Utečeno je sodelovanje z raziskovalci na geografskih in sorodnih raziskovalnih inštitutih doma in v tujini.

\section{PREDMETNIK}

\section{8. ŠTEVILO PREDMETOV}

Predmetnik podiplomskega študija geografije je sestavljen iz največ šestih predmetov (predavanja, seminarji, vaje) v celotnem študiju.

Program sestavljajo individualno kandidatom prirejene vsebine - posebej iz treh skupin predmetov:

- $\quad$ predmetov, ki so skupni za vse kandidate podiplomskega študija geografije (A),

- $\quad$ predmetov, ki so skupni vsem kandidatom določene izbrane smeri (B), in

- $\quad$ specialističnih predmetov, ki so za posameznega kandidata izbrani glede na temo magistrske naloge (C).

Predmeti prve skupine zajemajo teorijo, metodologijo in tehnologijo raziskovalnega dela $\mathrm{v}$ georafiji ter v družboslovju, humanistiki in naravoslovju nasplošno. Izvedba teh predmetov lahko poteka v organizirani obliki, tudi delno ali v celoti na ravni Filozofske fakultete ali skupin zainteresiranih oddelkov oziroma izven Filozofske fakultete v okviru Univerze. Predmeti druge skupine obravnavajo problematiko izbrane smeri, medtem ko so predmeti tretje skupine vsebinsko osredotočeni na pripravo magistrskega dela.

\section{LETNO IN CELOTNNO ŠTEVILO UR PROGRAMA}

Program magistrskega študija ima do 450 ur $(\mathrm{P}+\mathrm{S}+\mathrm{V})$, v prvem letniku praviloma do 300 ur, v drugem pa do 150 ur.

\section{VSEBINSKA STRUKTURA PREDMETNIKA (skupni predmeti za celoten} program, skupni predmeti za smer, skupine izbirnih predmetov, izbirni predmeti)

Možnosti oblikovanja programa po sistemu kreditnega ali individualnega študija:

A - Skupni predmeti podiplomskega študija geografije

- Izbrane kvantitativne metode v geografiji $15 \mathrm{KT}$

- Izbrana poglavja iz teorije in metodologije geografije $15 \mathrm{KT}$ 
B - Predmeti izbrane smeri

- Usmeritveni geografski predmet $15 \mathrm{KT}$

(Metodologija družbene, fizične, regionalne geografije ...)

- Usmeritveni predmet pomožne geografske vede $15 \mathrm{KT}$ (primer: Kraška hidrologija, Pravni vidiki prostorskega planiranja, Psihologija turizma in prostega časa, Politologija ...)

C - Specialistični predmeti

- Specialistični predmet I.

- Specialistični predmet II.

(interdisciplinarni oz. zunaj oddelčni predmet)

\section{POGOJI ZA VPIS (predizobrazba, posebni pogoji, omejitev vpisa)}

Na podiplomski študij geografije se lahko vpiše vsako leto do 20 kandidatov, ki imajo diplomo visokošolskega študija geografije oz. sorodnih smeri in so končali dodiplomski študij z nadpovprečnim študijskim uspehom (povprečna ocena nad 8) ali imajo ustrezne delovne izkušnje. Aktivno morajo obvladati vsaj en svetovni jezik.

Če imajo visokošolsko diplomo iz sorodne stroke, morajo v prvem letniku študija z ustnim diferencialnim izpitom dokazati, da poznajo osnovne strokovne probleme fizične, družbene in regionalne geografije ter študijskega področja na katerem se nameravajo strokovno poglabljati v času študija.

Pogoj za vpis je dokaz (potrdilo) o aktivnem znanju tujega jezika.

Pogoj za vpis je končanje dodiplomskega študija s povprečno oceno nad 8. Če je ocena nižja od 8 , se ustrezno upošteva tudi delovne izkušnje, npr. aktivno sodelovanje pri pomembnejšem strokovno-znanstvenem delu (raziskovalni tabori, raziskovalni projekti ipd.) oziroma ustrezna znanstvena in strokovna bibliografija. Za nadpovprečen dosežek se upošteva tudi katera od študentskih nagrad (priznanj) (fakultetna /univerzitetna Prešernova nagrada, Krkina nagrada, Priznanje Oddelka za geografijo ipd.) ali katero koli drugo priznanje za dosežke na strokovnem področju (npr. Ilešičeva in Melikova priznanja).

V primeru, da je prijav več kot je razpisnih mest, se izbor kandidatov naredi s postopnim izločanjem po naslednji hierarhični lestvici:

- ocena diplomskega dela,

- povprečna ocena izpitov iz geografskih predmetov na dodiplomskem študiju,

- vrednotenje bibliografije oziroma delovnih izkušenj.

\section{POGOJI ZA NAPREDOVANJE PO PROGRAMU (obveznosti in pogoji za napredovanje iz letnika $v$ letnik, za ponavljanje letnika, pogoji za podaljšanje statusa študenta; svetovanje in usmerjanje med študijem)}

$\mathrm{V}$ višji letnik študija se lahko vpišejo kandidati, ki so opravili vse obveznosti predpisane z individualnim študijskim programom, to je najmanj 45 kreditnih točk in so plačali šolnino 
ali imajo potrdilo, da so šolnine oproščeni. $V$ primeru, da niso opravili predpisanega števila kreditnih točk, imajo pravico do ponavljanja letnika. Če izpolnjujejo predpisane pogoje, lahko kandidati preidejo tudi neposredno na doktorski študij.

V. NAČINI IN OBLIKE IZVAJANJA PROGRAMOV (izredni študij, študij na daljavo; vzporedni, interdisciplinarni, individualni študij; kreditni študij...)

Podiplomski študij geografije poteka na osnovi individualnih študijskih programov, kot:

- kombinacija predavanj

- seminarjev in vaj ter

- konzultacij za nalogo in raziskovalno delo.

V primeru, da so za pomožne in specialistične geografske predmete organizirana redna predavanja (seminarji, vaje) na podiplomski stopnji na Filozofski fakulteti ali kateri od članic Univerze v Ljubljani ali na tujih univerzah, kandidati obiskuje te redne oblike dela (vključevanje v kreditni sistem študija). V primeru posebnih zahtev individualnega študijskega programa lahko podiplomski študij poteka tudi v obliki terenskega in laboratorijskega dela.

\section{POGOJI ZA DOKONČANJE ŠTUDIJA (zaključek študija, diploma)}

Kandidat, ki je vpisal podiplomski študij, mora pred zagovorom magistrskega dela uspešno opraviti vse obveznosti predpisane $\mathrm{z}$ individualnim študijskim programom (izpiti, seminarske, terenske, laboratorijske vaje). Študij je končan z uspešnim, javnim zagovorom magistrske naloge. V primeru doktorskega študija pa z uspešnim, javnim zagovorom doktorske disertacije.

\section{STROKOVNI, AKADEMSKI, ZNANSTVENI NAZIVI PO KONČANEM ŠTUDIJU}

Kandidat, ki konča podiplomski študij za pridobitev magisterija, dobi naziv "magister/magistrica znanosti". Kandidat, ki konča doktorski študij dobi naziv “doktor/doktorica znanosti”.

\section{VIII. ŠTEVILO VPISANIH ŠTUDENTOV MAGISTRSKEGA ŠTUDIJA}

Število vpisanih kandidatov na magistrski študij je vzpodbudilo Oddelek za geografijo, da je med prvimi na FF izpeljal redne oblike podiplomskega študija. Predavanja in seminarji so zadnja leta organizirana ob petkih popoldan. Letno je takšnih študijskih srečanj več kot deset. Na njih je dan poudarek aktivnemu sodelovanju študentov, ki morajo pred zagovorom magistrskega dela v seminarju predstaviti dve delovni fazi: zasnovo in prve rezultate magistrskega dela. Na ta način se javno preverja način dela pri izdelavi magistrskega dela in se hkrati dobiva dragocene izkušnje.

Število vpisanih študentov magistrskega študija po usmeritvah v obdobju 2000 - 2004

$\begin{array}{llll}\text { Didaktika geografije } & 1 & \text { Ekološka geografija } & 11 \\ \text { Fizična geografija } & 5 & \text { Geografija krasa } & 2\end{array}$


$\begin{array}{llll}\text { Regionalna geografija } & 3 & \text { Geografija turizma } & 4\end{array}$ Geografske osnove regional. Planiranja $6 \quad$ Socialna in politična geografija 18

V štiriletnem obdobju, ki je predstavljeno v preglednici, se je število vpisanih študentov na podiplomski študij skokovito povečalo. Pred tem časom njihovo število ni doseglo 10, po letu 2000 pa se je dvignilo na povprečno 13. Razporeditev študentov po usmeritvah je zelo neenakomerna. Najmočneje je zastopana socialna in politična geografija, ki pa združuje zelo široko tematiko. Vsebinsko bolj homogena je naslednja najmočnejša skupina: ekološka geografija.

Oglejmo si za primer naslove magistrskih del s področja socialne in politične geografije v obdobju 2000 - 2004:

- Socialnogeografska problematika slovenske Koroške in njenih prostorskih vezi s sosednjimi regijami.

- Med politično reorientacijo in mednarodno integracijo - izbrani vidiki širjenja Evropske unije v Srednji Evropi.

- $\quad$ Spremembe sestave družin v Sloveniji po drugi svetovni vojni.

- Socialnogeografska preobrazba podeželja v brežiški občini.

- Regionalizacija v Sloveniji s poudarkom na obmejnih regijah v luči evropskih integracij.

- Uporaba digitalnih ortofoto posnetkov za proučevanje spreminjanja morfologije in širjenja mesta Ljubljana.

- $\quad$ Vpliv regionalne politike na razvoj prostorske strukture v Sloveniji: teorije, modeli in aplikacija.

- Ilegalne mednarodne migracije v luči sodobnih družbenih in političnogeografskih transformacij na primeru Evrope in Slovenije.

- Meja kot ovira in dejavnik družbenega razvoja - primer jugozahodne Slovenije.

- Geopolitična vizija Jugovzhodne Evrope v 21. stoletju.

- Geografske značilnosti kriznih območij v državah nekdanje sovjetske Osrednje Azije.

- Vplivi okoljskih ukrepov na pokrajino.

- Problematika družbenoprostorske vloge Slovencev v Italiji v luči slovenske kulturne politike.

- $\quad$ Prostorski učinki manjšin in migrantskih skupnosti ob vzhodni poljski meji.

- Globalizacija, migracije in multikulturnost v migracijskih območjih: primerjalna študija med Nizozemsko in Slovenijo.

- Zaraščanje kulturne pokrajine v Sloveniji.

- Demogeografsko proučevanje navadnih in etničnih manjšin.

- $\quad$ Nasledstvena struktura hribovskih kmetij v Sloveniji.

Vse več študentov se na podlagi predlogov mentorjev usmerja na neposredni doktorski študij. Najtežja ovira pri tem prehodu je poleg redno izpolnjene večine izpitnih obveznosti, predpisanih za magistrski študij, predvsem objava znanstvene razprave v priznanem strokovnem glasilu.

Marijan M. Klemenčič 